\title{
Chapter 6 \\ Fluorescence Observables and Enzyme \\ Kinetics in the Investigation of PPI \\ Modulation by Small Molecules: \\ Detection, Mechanistic Insight, and Functional Consequences
}

\section{Glauco Ponterini}

\subsection{Introduction}

Protein homo- or hetero-oligomers are widespread in living systems. In many instances, their functional roles have been established or conjectured [1,2], and the potential impact of their study on the understanding of apparently unrelated phenomena, such as protein folding and inter-domain interaction, has been underlined [3]. The discovery of small molecules able to modulate protein-protein interactions (PPIs), hence changing the stability of the oligomers, may therefore assume a strong functional significance. However, PPIs often involve extended protein interfaces which have long been perceived as chemically featureless; therefore, designing small molecules with a potential to interfere with high affinity and specificity with a multiprotein complex, and modulate its stability, may represent a challenging chemical problem having functional biological implications [2, 4-7]. Fortunately, the above perception is increasingly refuted [8, 9], and examples of small compounds able to bind to a protein surface with affinities high enough to compete with the binding of the protein to other proteins are rapidly accumulating $[2,4,6-8,10$ and Chap. 2 in this book]. A qualitative/quantitative characterization of the effects of these compounds on protein-protein complex formation is essential in drug discovery processes targeting PPIs and, as we shall see, has been obtained through several experimental approaches. On the other hand, addressing and characterizing the mechanism of action of such small molecules, including the relevant structural features, often remains a prohibitive task. However, it is this higher level of knowledge that, while answering intrinsically relevant questions related, for example, with the types and number of PPIs involved, may provide valuable hints

\footnotetext{
G. Ponterini $(\bowtie)$

Department of Life Sciences, University of Modena and Reggio Emilia, via Campi 183, 41125 Modena, Italy

e-mail: glauco.ponterini@unimore.it
} 
for designing new small molecules characterized by stronger, or more specific, modulating actions [10].

Essentially, any biophysical experimental observable, whether associated with light-matter or electron-matter interactions (absorption, both molecular and plasmonic, emission, scattering, diffraction), with heat exchange, with molecularsize-dependent radial distribution in a rotating centrifuge, or migration in a chromatographic column or under an electric field, can in principle be employed to investigate PPIs, and many of them have actually been so [11-14]. On the other hand, most reported examples of modulation of these interactions by small molecules are based on experimental methods that probe a narrower group of biophysical observables, especially those adaptable for protocols with highthroughput-screening capacities [15]. Designing and setting up an experimental method that is able not only to give a signal when testing an active compound, but also to provide structural and/or functional insight on the effects of its binding on PPIs, that is, on the structure/stability of supramolecular protein assemblies, can be severely challenging. Such a method must fulfill the requirements for detecting and characterizing PPIs, but with a few important additions: It should be sensitive enough to reflect changes in these interactions that (1) may be intrinsically small and (2) are often produced in ligand/protein complexes present at much lower concentrations than the unperturbed protein oligomers. This requirement is particularly severe in the many examples of functional relevance in which transient multimeric protein assemblies are addressed and weak to moderate PPIs that govern their formation are modulated [16]. Finally, and rarely achieved, (3) the experimental approach should also provide mechanistic insight, that is, it should highlight the changes in structure and behavior brought about in the protein assembly by the binding to the small molecule.

In the reported examples of PPI modulation, spectroscopic methods are most often employed for the purpose, being naturally connected with the structure of the molecules probed and the interactions they experience and, at least in many favorable cases, because of their good sensitivity and specificity. Noteworthy exceptions are represented by studies based on size-exclusion chromatography (SEC), sedimentation equilibrium analytical ultracentrifugation, usually in the sedimentation velocity mode of measurement [17], and surface plasmon resonance (SPR). The first two techniques are based on a spatial separation of protein monomers and different multimers and have found some applications in the field of PPI modulation screening (some cases are described in Ref. [18]). However, because of complicating effects (e.g., in SEC, nonspecific binding of differently aggregated proteins to the stationary phase may differentially affect the chemical potentials of monomers and different multimers [19]), and, more generally, because of the competing tendency of the system to locally re-establish the aggregation equilibrium, thus blurring the desired size-based spatial separation, these methods require an optimization of the experimental conditions and a careful calibration and data analysis to yield reliable quantitative data [20,21]. SPR has become a widespread method to monitor formation/dissociation of protein complexes [22] and, in a few examples, to screen the effects thereon of libraries of 
small molecules (see, e.g., Refs. [23] and [24]). In this technique, the rate constants for association and dissociation of an added compound to an immobilized partner are usually evaluated from the time evolution of the observable, and, from their ratios, binding equilibrium constants are estimated [25]. SPR suffers from a few limiting features; for example, irreversibility of ligand/target complex formation and, relevant to our subject, the occurrence of other processes following binding, such as protein-protein complex formation or dissociation, represent undesired events that complicate data fitting. Also, the SPR observable consists in shifts in the resonance wavelength of gold surface plasmons caused by the binding of organic molecules on the metal surface. It is not, therefore, a molecular spectroscopic technique and can hardly provide a molecular-scale insight comparable with that obtainable from spectroscopic tools. Among the latter, methods based on nuclear magnetic resonance (NMR) $[16,26]$ and on molecular fluorescence (see, e.g., Ref. [27]) are the most powerful and most often employed. Both families of approaches can provide direct insight into the structural details and the dynamics of protein-protein and protein-ligand complexes, though with their specificities, advantages, and limitations. NMR applications are described elsewhere in this volume (Rebecca Del Conte, Daniela Lalli, Paola Turano, NMR as a tool to target PPIs). Here, we have collected and commented on some representative examples of the potential of fluorescence-based methods in the screening and molecularscale mechanistic investigation of PPI modulation by small molecules (this overview is intended to be by way of example rather than exhaustive).

From a quite different point of view, when multimeric enzymes are involved, kinetic analyses can be employed to screen the functional consequences of the modulation of PPIs by small molecules and, more relevant in the perspective of this contribution, to test mechanistic hypotheses. The potential of this experimental opportunity has probably been overlooked. In the final part of this chapter, we will briefly and critically review some relevant examples.

\subsection{Fluorescence Observables}

These experimental approaches take advantage of a variety of observables. Properties such as spectra, intensities (related to quantum yields), time-decays, and anisotropies of intrinsic protein fluorophores, of extrinsic fluorescent tags and, even, of the same small molecules added to modulate PPIs, as well as phenomena such as static and collisional quenching, including electron and excitation-energy transfer, or exciton interaction, whose efficiencies crucially depend on the distance between the partners and their relative orientation [28, 29], may in principle be used to monitor changes in the protein aggregation pattern. 


\subsubsection{Protein Fluorescence}

Changes in properties of the intrinsic fluorescence of proteins related with changes in their aggregation state (Fig. 6.1) have been reported, and exploited, in quite a few instances. Pertinent examples are the cases of interferon- $\gamma$ dimer/monomer transition, of calmodulin interaction with a neuronal target protein (see Ref. [29], Chap. 16), of melittin self-association (see Ref. [29], Chap. 17), and of the complexation of a retinal phosphodiesterase subunit with two subunits of heterotrimeric G-protein transducin [30].
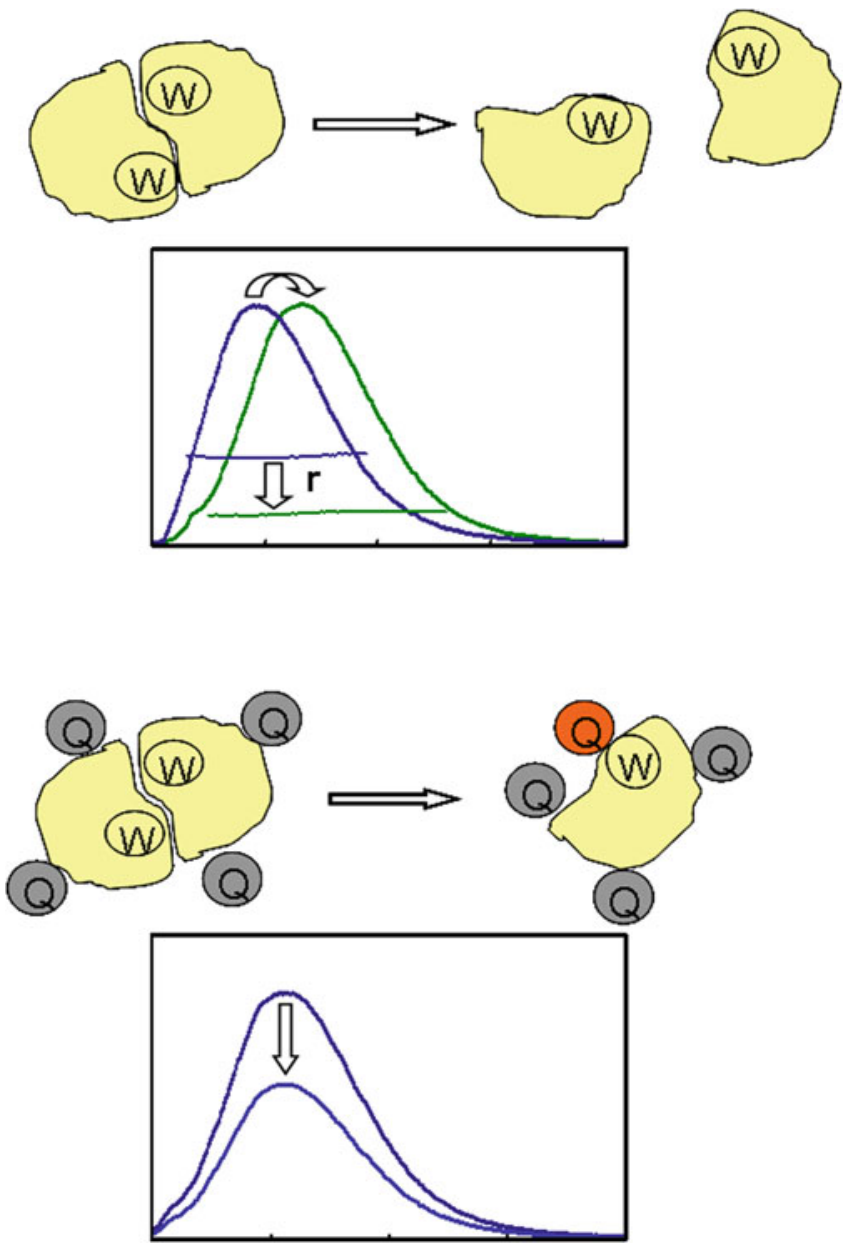

Fig. 6.1 Protein multimer disruption and steady-state intrinsic (tryptophan, $W$ ) protein fluorescence. Top emission spectral shift associated with a change in $W$ environment; change in anisotropy related with a change in rotational mobility. Bottom decrease in emission intensity due to increased accessibility of external quenchers $(Q)$ to $W \mathrm{~s}$ 
Because of the different electronic distributions of the lowest excited $\left(\mathrm{S}_{1}\right)$ and ground electronic states, of the possible involvement of $n \pi^{*}$ states and of possible free-volume-requiring $S_{1}$-state relaxation processes, emission spectra are often sensitive to the polarity, proticity, and microviscosity of the fluorophore environment. The main intrinsic fluorophore of proteins, tryptophan, exhibits such a sensitivity: Its emission shows a bathochromic shift with increasing polarity of the local environment (upper panel in Fig. 6.1), and a blurring of the vibronic structure when moving from an aprotic to a protic environment, associated with the stabilization of the ${ }^{1} \mathrm{~L}_{\mathrm{a}}$ relative to the ${ }^{1} \mathrm{~L}_{\mathrm{b}}$ states (see Ref. [29], Chap. 16). Thus, the intrinsic protein emission spectrum can be used to monitor changes in the solvent exposure of the tryptophan residues. In the only example known to us of PPI modulation by small molecules monitored in this way, shifts of the emission maximum of glutamate dehydrogenase enabled a reversible hexamer-to-trimer dissociation of the protein to be observed. The approach, based on dynamic light scattering, aimed at progressively disrupting PPIs using guanidinium hydrochloride at low concentrations. Increases in $\Delta \mathrm{Gs}$ were estimated for the process upon binding of norvaline and glutamate to the protein, indicating a ligand-induced stabilization of the hexamer [31], a rare example of positive modulation of PPIs by small molecules.

Measuring changes in intensity of the intrinsic protein fluorescence in complexes relative to the corresponding separated components seems quite a simple way to monitor complex formation or disruption (see, e.g., Ref. [30]). In spite of this, we are aware of only one example of small-molecule-induced changes in protein complexation investigated this way. A combination of SEC and intrinsic protein fluorescence measurement showed that tethered peptides, corresponding to the N- and C-termini of HIV-1 protease, targeted the dimer interface of HIV-1 protease and decreased the fraction of enzyme dimer in solution [32]. Here, the presence of a tryptophan near the monomer/monomer interface was exploited: Addition of the tethered dipeptide inhibitor to the protein caused a marked fluorescence quenching that was not observed with a conventional active-site inhibitor and was presumed to be due to an 'increased solvent exposure' of this tryptophan in the monomers. This statement is probably misleading, as it suggests that exposed tryptophans are more likely quenched than are more buried ones. This is true when accessibility by external quenchers, such as acrylamide or oxygen, is concerned (see Ref. [29], Chap. 16 and the following lines). However, it is well known that the lifetimes and quantum yields of tryptophans in proteins are controlled by a number of quenching processes that involve several different residues, as well as peptide bonds of the backbone [33]. As a result, lifetimes and quantum yields do not correlate with emission maxima, that is, with the solvent exposure of the tryptophans (see Ref. [29], Chap. 16). So, in principle, these observables could be exploited to monitor changes in the aggregation state of the proteins if these result in structural changes that occur in the proximity of tryptophan residues, even buried ones, and that, in turn, affect the efficiency of the quenching processes.

Protein fluorescence quantum yields are reduced in the presence of dissolved quenchers that can access one or more tryptophans. Thus, measurements of protein 
emission intensity in the presence of dissolved quenchers can reveal changes in accessibility resulting from formation or disruption of protein complexes (lower panel in Fig. 6.1). For example, increased quenching by KI of the intrinsic fluorescence of Plasmodium falciparum triosephosphate isomerase, following mutation of a tyrosine at the subunit interface to glycine, indicated a larger accessibility by the iodide quencher in water of a tryptophan residue near the interface, associated with dimer disruption, as confirmed by gel filtration experiments [34]. In a slightly different approach, the tetramer-to-dimer and dimer-to-monomer dissociation kinetics of three apolipoproteins of the $E$ family were followed by observing the decrease in intensity of the intrinsic protein fluorescence following dilution of the proteins in a solution of acrylamide, a classical tryptophan quencher [35]. In spite of the potential of this fluorescence observable, we are not aware of the use of experiments based on differential accessibility to quenchers to test PPI perturbation by small molecules.

In general, the intrinsic steady-state protein fluorescence properties, most notably anisotropy (upper panel in Fig. 6.1), are little employed to monitor changes in the protein aggregation pattern caused by interaction with small molecules, in spite of the simplicity of these measurements. The small number of examples of this kind might imply that the tryptophan emission properties are rarely significantly affected by changes in the tertiary and quaternary structure of proteins. We are not, however, aware that this has ever been actually observed and explicitly reported.

\subsubsection{Fluorescence of Probes}

When fluorescent labels are employed, the source of information about changes in PPIs, or in protein assemblies, is a change in the probe fluorescence properties. In order to provide information of mechanistic relevance, such changes must be traceable to varied probe environment, accessibility to quenchers, proximity to other fluorophores or rotational mobility.

As an example of a change in a probe environment, a fluorescence assay has been designed to test the binding of a library of tetrapeptides, modeled on the $\mathrm{N}$-terminus of the pro-apoptotic protein Smac, to the surface pocket of the BIR3 binding region of the anti-apoptotic XIAP protein. Here, a solvent-sensitive fluorogenic naphthalene-based dye was attached to a tetrapeptide through a thiol linkage and, upon binding to XIAP, underwent a solvatochromic emission shift and a change in emission intensity (upper panel in Fig. 6.2). These changes, or, more precisely, their reversal (lower panel in Fig. 6.2), were employed to monitor the displacement of the bound tagged peptide by other untagged tetrapeptides, and quantify the corresponding binding equilibrium constants [36].

Anisotropy changes, which reflect changes in rotational mobility of the fluorophore in the free and bound states or, with lower sensitivity, when bound to a protein in different aggregation states, have been employed to characterize small 

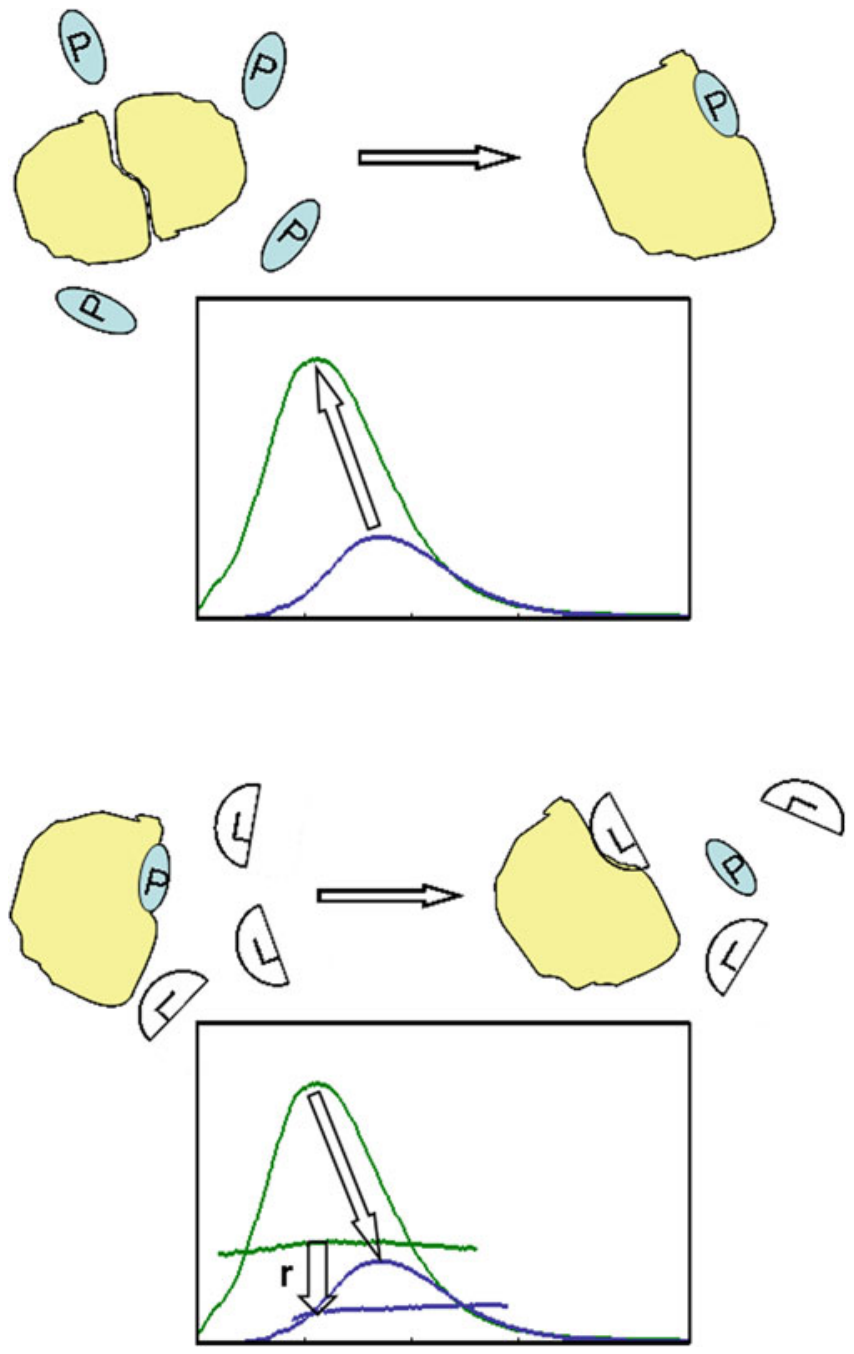

Fig. 6.2 Top protein multimer disruption and steady-state probe fluorescence: emission spectral shift and intensity change associated with a change in probe environment. Bottom reversed spectral changes and decrease in probe emission anisotropy caused by mass-law-governed displacement of the probe by a tested ligand $(L)$. Here, $P$ represents a fluorescent probe or, more often, a tagged peptide with good affinity for the protein-protein binding site

inhibitors of PPIs. An example of the latter kind is provided by self-association of a fluorescein-labeled retinoid-X-receptor to form tetramers that was followed by measuring the fluorescence anisotropy of the probe with increasing protein concentration. In the presence of 9-cis-retinoic acid, the final anisotropy was much lower than in its absence, an indication that formation of the tetramer, characterized by a slower rotational diffusion, was inhibited by this ligand [37]. A similar 
fluorescence polarization assay, developed in a high-throughput format, was employed to screen compounds able to perturb the interaction between two peptides, designed from the binding regions of fibronectin and tissue transglutaminase, two proteins whose complex is believed to promote tumor cell adhesion and to be involved in the process of tumor dissemination [38]. One of the two peptides was tagged with a fluorescein molecule; addition of the other peptide resulted in a saturating increase in the anisotropy of the probe, due to complex formation. Small compounds able to inhibit formation of the complex caused a decrease in the observed anisotropy at fixed peptide concentrations.

The most widely employed fluorescence polarization assays are, however, based on competitive displacement of a labeled small molecule, often a peptide, known to bind at a region crucial for PPI (lower panel in Fig. 6.2). Rather than directly monitoring PPI modulation, the assay aims at testing the ability of small molecules to replace the labeled small molecule, which is assumed to mimic the partner protein. For example, some peptides designed from pro-apoptotic Smac were shown to bind to the BIR2 and BIR3 domains of the anti-apoptotic XIAP inhibitor protein [39-41]. This binding was quantitatively characterized by measuring the anisotropy of the emission from a peptide labeled with a carboxyfluorescein, which was progressively displaced from the BIR2 and BIR3 domains of XIAP by the tested unlabeled peptides in dose-response experiments. Similarly, the $\mathrm{IC}_{50} \mathrm{~S}$ of two small peptide-based inhibitors of the interaction between the von Hippel-Lindau protein (VHL), the substrate recognition subunit of an ubiquitin ligase, and its primary substrate, the hypoxia-inducible factor $1 \alpha(\mathrm{HIF}-1 \alpha)$, were determined by measuring the anisotropy of a fluorescein-labeled HIF- $1 \alpha$ peptide that binds VHL with a $560 \mathrm{nM}$ affinity [42]. In another example, inhibition constants of several green tea polyphenols versus two Bcl-2 family anti-apoptotic proteins were determined with a competition assay based on dose-dependent displacement of a fluorescein-labeled peptide, reproducing the $\mathrm{BH} 3$ domain of the pro-apoptotic counterparts, and measurement of the resulting decrease in emission polarization of the fluorescein probe [43]. Essentially, the same approach has been employed [44, 45], also in a high-throughput version [46], to find inhibitors of the $\mathrm{BH} 3 / \mathrm{Bcl}-2$ interaction, to identify chelerythrine as an inhibitor of the Bcl-XL/BH3 complexation [47], to screen a series of terephthalamides as inhibitors of the Bcl-XL/BAK peptide binding [48], to test molecules, selected using a shapecomparison program, for activity against the ZipA-FtsZ interaction, an antibacterial target [49], and to identify a small inhibitor of the interaction between one of the proteins of the 14-3-3 family, implied in physiological and pathophysiological interactions with more than 200 proteins, and the pS259-Raf-1 peptide [50]. The additivity of fluorescence anisotropy [28] was crucial in some of these applications to enable the fractions of labeled peptides, bound and free, and the binding equilibrium constants to be determined. A problem with this kind of assay is that, in order to characterize quantitatively the binding of potent inhibitors, high-affinity labeled peptides, to be replaced by the tested compounds, must sometimes be designed and obtained for the purpose [41]. As a general comment on the widespread methods based on polarization of probe fluorescence, while 
these experiments are efficient as bases for medium- to high-throughput screenings (HTS), because they rely on rotational mobility, which is controlled mainly by size and, to a lesser extent, shape, they generally lack structural/mechanistic insight on the protein/ligand binding modes.

Under favorable conditions, H-type exciton coupling between closely associated fluorescent labels may result in a marked emission quenching [51]. This phenomenon was exploited to monitor the dissociation kinetics of a subunit from trimeric tumor necrosis factor $\alpha$ induced by a small inhibitor of the protein and to deduce conclusions on the mechanism of the process [52]. Dissociation of a subunit caused loss of H-type exciton coupling between fluorescein molecules labeling different subunits and resulted in emission recovery.

A couple of examples of PPI modulation by small molecules are characterized by a hazy description of the molecular bases of the assay employed. In the first one, a change in fluorescence from a probe was only assumed to reflect changes in a protein assembly, but was not interpreted on a molecular level. The fluorescence of dansylated L. casei thymidylate synthase (TS) was monitored to investigate structural changes of the dimeric protein upon interaction with a 20 -mer peptide designed to reproduce a sequence at the subunit interface [53]. Addition of this peptide, that inhibits TS, was found to result in a decrease in the emission intensity of a dansyl probe specifically bound to a Cys residue which resides at the dimer interface. However, both this quenching and the protein inhibition were attributed to a peptide-induced decrease in spectroscopically and kinetically observable labeled protein in solution due to aggregation/precipitation, rather than to interference of the peptide with protein dimer structure or stability. A similar lack of molecular-scale insight characterizes an affinity-based assay proposed as a screening tool for PPIs [54]. A change in fluorescence intensity of a 'generic probe' upon thermal denaturation of a protein to which it is bound was employed in a high-throughput miniaturized test. An increase in thermal stability was expected and observed as a consequence of the binding of a tested compound to the labeled target protein. This small-molecule binding possibly but not necessarily inhibited binding with other proteins.

A rare example of the use of fluorescence changes to investigate the ability of small molecules to inhibit protein-protein binding is provided by the competition between antimycin A and the pro-apoptotic proteins BAK, BAX, and BIK for binding to the hydrophobic grooves of Bcl-XL [55] or of a recombinant Bcl-2 [56], anti-apoptotic proteins overexpressed in many cancer cells. In these cases, it was an emission enhancement of antimycin A itself, that is, the small inhibitor of proteinprotein association, that was employed to demonstrate its binding to the $\mathrm{Bcl}$ proteins. The assumption was that the emission quantum yield of this fluorophore is larger in the hydrophobic environment provided by the proteins. Conversely, in competition experiments, a decrease in emission from antimycin A was used to monitor binding of a nonfluorescent methoxy derivative to the same groove. In the second paper, parallel experiments were made with 1-anilino-8-naphthalene sulfonate, a widely employed hydrophobic probe with emission properties that are strongly environment dependent. 
Another example of fluorescent small PPI modulator is a fluorene-based compound able to block the interaction between $\alpha 2 \beta 1$ integrin and collagen, an interaction that has been shown to have an important role in thrombus formation and cancer spread [57]. The peculiarity and interest of this example come from the fact that this inhibitor was specifically designed in order not only to bind to the flat collagen-binding domain of the integrin but, also, to be fluorescent. This condition is not, however, sufficient to make a good self-probing small inhibitor. In addition, some property of the fluorescence must change upon binding of the small molecule to the target protein domain. In this case, a strong emission enhancement accompanied the binding, a result not easily predictable. A molecular structure composed of one or more fluorophores connected to a biologically active group through single bonds, which allow for some torsion, is probably a useful structural feature for a fluorophore that is desired to have its emission quantum yield increased in a constrained environment. A similar feature characterizes some wellknown fluorescent DNA dyes, for example, Hoechst 33258 [58]. Finally, but importantly, some evidence must be available about the ability of the bound fluorescent molecule to modulate the binding affinity of the protein toward other proteins.

\subsubsection{Bimolecular Processes: FRET}

Measurement of the efficiency of fluorescence (or Förster) resonance energy transfer (FRET), a long known powerful method for obtaining information about molecular-scale distances [28], is the most widely employed fluorescence-based method to investigate protein-protein complexation equilibria. Typically, selective excitation of an excitation-energy donor results in emission from an acceptor with an efficiency that depends on distance and relative orientation. Measurement of this efficiency for a well-characterized donor-acceptor pair enables distance between the partners to be estimated under reasonable assumptions on their relative orientation. FRET between fluorescent partners, including proteins, can be quantitatively assessed both in steady-state and in time-resolved (TR) experiments $[28,59]$. In the former, the donor and acceptor emissions are measured under continuous excitation, either as full spectra or, in higher-throughput screenings, as intensities at selected excitation and emission wavelengths. Steady-state FRET experiments may be employed to investigate the association/dissociation kinetics of multimeric proteins when these kinetics are slow relative to mixing/dilution times [35]. TR experiments consist in acquiring the fluorescence time profiles following pulsed excitation and analyzing them to derive FRET efficiencies from changes in fluorescence intensity decays (donors) or rises (acceptors). FRET experiments can also be performed on living cells by combining steady-state or TR fluorescence measurements with the spatial resolution of a conventional optical or a confocal microscope $[28,60]$. As one of the many examples of experiments designed to monitor PPI in cells, steady-state FRET between two different mutants 
of GFP fused to two human Four-and-a-half LIM-only proteins, FHL2 and FHL3, was employed to determine their interaction and to locate the site of this interaction in a single intact mammalian cell [61].

There follows a selection of examples of FRET-based experiments, designed to monitor modulation of PPIs by small molecules.

FRET from fluorescein to tetramethylrhodamine, selectively bound to two cysteine residues, each on a different monomer of dimeric human TS (Fig. 6.3), was exploited in concentration-dependent steady-state fluorescence measurements to determine the fraction of dimeric protein at each total protein concentration and, as a result, the monomer/dimer equilibrium constant [62]. The assay was then used to test whether some octapeptides, found to inhibit hTS through an unconventional mechanism, were able to disrupt the protein dimer [63]. The experimental results showed only a minor perturbation of FRET, consistent with the crystallographic evidence of a binding of the peptides at the subunit interface without causing significant destabilization of the protein dimer.

A small library obtained by computational interrogation of the binding pocket of protein S100A10 was screened to identify compounds able to destabilize the complex between S100A10 and the phospholipid-binding protein Annexin A2 [64]. Steady-state FRET from Cy3-labeled Annexin A2 and Cy5-labeled S100A10 was employed in the screening. In this case, S100A10 protein labeling was not site directed, and its stoichiometry was only roughly defined. So, while fairly easily achieved, such an approach can only provide semiquantitative information on the efficacy of the tested small compounds in destabilizing the protein association.

FRET between two fluorescent probes, bound to the antibodies for two different epitope tags linked to the two monomers of HIV-1 integrase (IN), earlier used to characterize the monomer/dimer equilibrium of this protein [65], has later been combined with an equilibrium analysis of a binding model for IN-IN interaction, including the monomeric and several oligomeric species in the presence of an INdimer ligand. Dithiothreitol and $\beta$-mercaptoethanol weakened the IN monomermonomer interaction. On the other hand, two peptides derived from LEDGF, a cellular cofactor that interacts with the IN-dimer interface, and a small molecule, all of which compete with LEDGF for binding to IN, were found to increase the stability of the IN dimers [66].

A nice example of the use of FRET, in combination with fluorescence microscopy, to monitor the effects of small compounds on PPIs in living cells is provided by the investigation of the effects of compounds, previously found able to disrupt $\mathrm{BH} 3$ interactions in vitro, on the heterodimerization of Bcl-XL with the pro-apoptotic proteins, BAX and BAD [46]. Intact cells were co-transfected with the expression vectors BAX fused to yellow fluorescent protein (YFP) and Bcl-XL fused to cyan fluorescent protein (CFP). Co-transfection resulted in an increase in the YFP-to-CFP emission ratio, relative to separately transfected cells, due to CFP-to-YFP energy transfer. The addition of the above compounds caused decreases in this 'FRET ratio' consistent with the activities of the compounds in vitro. The same approach, only involving different FRET donor and acceptor, 


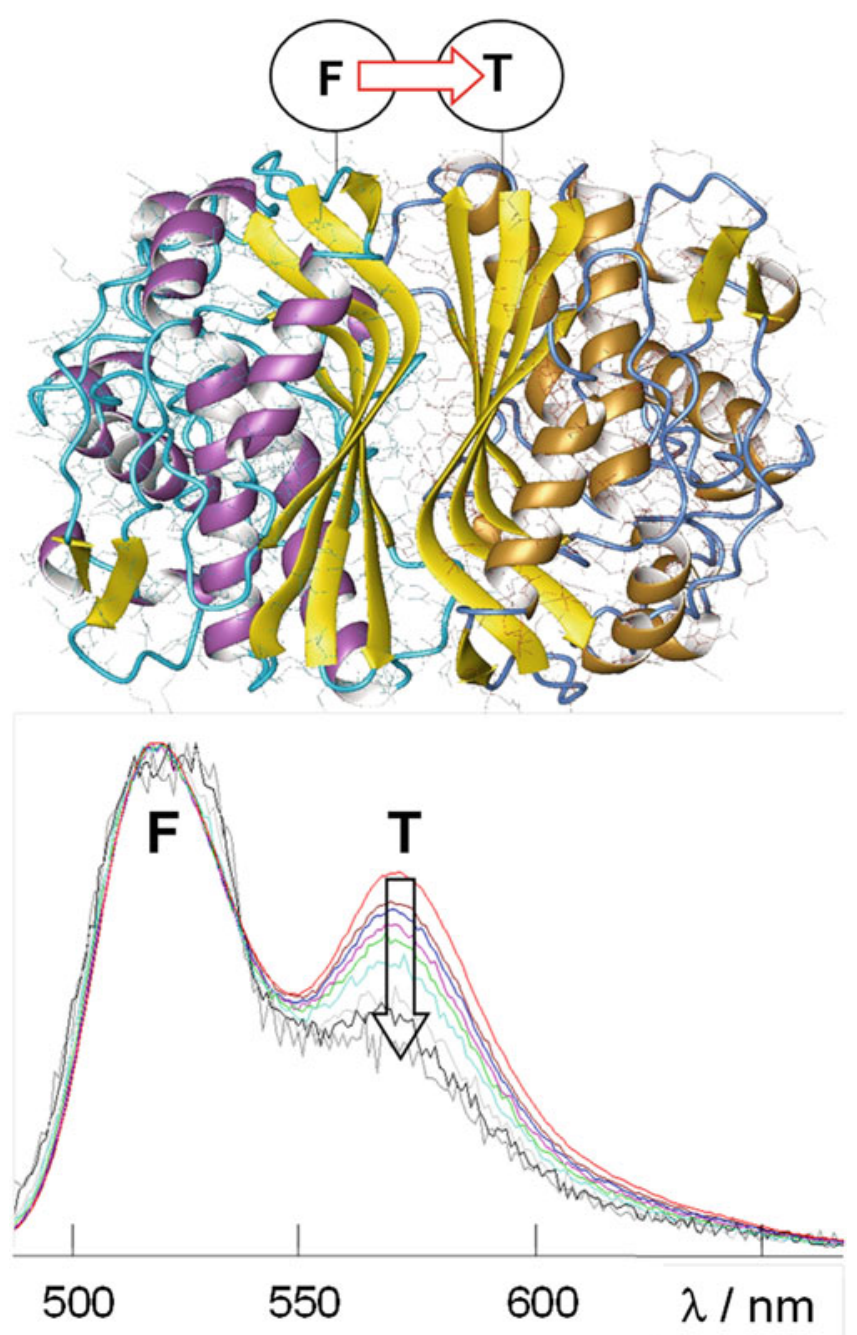

Fig. 6.3 FRET from fluorescein $(F)$ to tetramethylrhodamine $(T)$ bound to Cys 43 and 43 ' of the human thymidylate synthase dimer. FRET efficiency is correlated with the relative T/F emission intensity and decreases with decreasing total protein concentration, from ca 300 to ca $5 \mathrm{nM} \mathrm{[} \mathrm{62]}$

was employed to test the effects of the same compounds on heterodimerization of $\mathrm{BAD}$ with either Bcl-2 or Bcl-XL in intact cells.

Changes in the efficiency of homo-FRET, that is, excitation-energy transfer between a donor and an acceptor of the same chemical nature, such as two tryptophan residues or two extrinsic, identical probes in a protein oligomer, including homo-oligomers, may reveal changes in the protein oligomerization state [67]. Here, it is the depolarization associated with excitation-energy transfer between like fluorophores that is usually measured [28]. As a clever example of the use of 
homo-FRET to investigate the effect of small molecules on protein oligomerization, we mention the case of the $\operatorname{serotonin}_{1 \mathrm{~A}}$ receptor whose oligomers are potentially implicated in the functional roles of the protein. Homo-FRET and fluorescence lifetime measurements have been used to monitor such an oligomerization in cells expressing the serotonin $\mathrm{n}_{1 \mathrm{~A}}$ receptor tagged to enhanced yellow fluorescent protein [68]. The emission anisotropies were found to be lower than the value predicted for the monomeric protein, and the depolarization was attributed to homo-FRET within protein oligomers. To support this assignment, the fluorophores were progressively photobleached. Because the efficiency of homo-FRET correlates with the spectral absorption/emission overlap, the bleaching led to recovery of anisotropy. This was analyzed versus predicted recoveries for collections of dimers, trimers, and higher aggregates. This analysis, combined with the extrapolated anisotropies at full fluorophore photobleaching, enabled the authors to discriminate between oligomers of different sizes. In particular, they tested the effects of some known agonist and antagonists of the serotonin receptor and found that while treatment with an antagonist (p-MPPI) lowered the fraction of higher-order oligomers, the agonist (serotonin itself) induced the formation of higher-order oligomers. Homo-FRET combined with microscopy, and, in some instances, with the increased selectivity afforded by two-photon excitation, has recently provided subcellular resolution imaging of protein oligomers [69, 70].

Conventional, steady-state FRET measurements may suffer from limited accuracy because of interfering emissions, particularly from complex biological samples. An impressive increase in sensitivity has been obtained by employing longlived fluorophores, mostly lanthanide ions, to enable time-gated measurements of the donor/acceptor signals delayed, with respect to excitation, from several microseconds to a few milliseconds, that is, a time when all background, usually nanosecond, emissions have decayed [71, 72]. Biosensors based on nanocrystals doped with lanthanides have been proposed for this application [72]. A similar increase in analytical robustness is obtained using a bioluminescent excitation-energy donor, typically, a luciferase (BRET, [13]). Here, intensities are extremely low, but interferences are essentially absent, as no excitation light is required. The methods are well suited for medium-to-high throughput screenings. An example of the first approach, often, and rather confusingly, called time-resolved FRET (TR-FRET), consists in the screening of 1,280 compounds to identify inhibitors of the dimerization of a 106-residue domain of the capsid protein of hepatitis $\mathrm{C}$ virus [73]. The Core-106 fragments were tagged with an N-terminal glutathione-S-transferase (GST) or Flag peptide. Europium cryptate, a long-lived donor, and allophycocyanin were used to label anti-GST and anti-Flag antibodies. Association between GSTcore106 and Flag-core106 was assessed by measuring FRET between the two fluorophores following antigen/antibody recognition. Another example is provided by the discovery of potent, nonpeptide inhibitors of the interaction between leukocyte function-associated antigen-1 (LFA-1), a member of the $\beta_{2}$-integrin family of adhesion molecules, and intracellular adhesion molecule ICAM-1 [74, 75]. In this case the strategy consisted in immobilizing one of the two partners, tagged with a fluorescent probe, and adding the other partner, tagged with a long-lived europium 
luminophore using the biotin/streptavidin recognition. The decrease in FRET observed in the presence of screened compounds was a measure of the ability of the latter to disrupt the LFA-1/ICAM-1 interaction. Several more HTS TR-FRET assays differing only in some details, say, the nature of the donating lanthanide and the accepting fluorophores or the strategy to tag the interacting proteins with the two fluorophores, have been applied to search for small PPI inhibitors. An $\mathrm{Eu}^{3+}$ cryptateconjugated anti-FLAG antibody and an anti-6His antibody conjugated to a fluorescent excitation-energy acceptor have been employed in an assay designed to screen approximately 15,000 compounds to find inhibitors of the complexation of FLAG-fused IKK $\beta$ with NEMO-6His, a process involved in inflammatory and autoimmune disorders [76]. A $\mathrm{Tb}^{3+}$ chelate and Alexa Fluor 488 have been chemically conjugated, respectively, to the $G$ protein, $G \alpha_{o}$, and its regulator protein, RGS4, and used in a TR-FRET screening of approximately 40,000 compounds to find two inhibitors of this PPI [77]. An europium-labeled anti-His antibody and a streptavidin-conjugated APC fluorophores were employed to label the 6HisapoRBP4 and the biotinylated human TTR proteins to test small compounds that were found to either increase or decrease the affinity of the retinol-binding protein, RBP4, for transthyretin, TTR [78].

\subsubsection{Multiple and Other Fluorescence Observables}

The above-mentioned fluorescence observables may be usefully combined within the same investigation. An example is provided by the screening of 60 compounds that had been previously selected by computational methods as possible inhibitors of the down-regulation of the p53 tumor suppressor protein caused by interaction with the calcium-binding protein, S100B [79]. Complexation of the latter with the small compounds, leading to p53 activity increase, was monitored by four different titration experiments: direct measurement of emission changes from the fluorescent compounds due to subsequent additions of the S100B protein; quenching of tyrosine emission from the protein upon titration with the compounds; measurement of tryptophan emission restoration in competition titrations of wild-type S100B into solutions of the complexes of an S100B tryptophan mutant with the small compounds; and measurement of fluorescence from a peptide derived from p53 (F385W) that binds holo-S100B in competition titrations of the small molecules to the S100B-p53 complex.

Another example of combination of fluorescence observables is provided by the screening of small-molecule inhibitors that interfere with the cytohesin-catalyzed GDP/GTP exchange on a truncated version of ARF1, an adenosine diphosphate ribosylation factor (ND17ARF1) and/or with the interaction between $\mathrm{N} \Delta 17 \mathrm{ARF} 1$ GTP and its effector protein GGA3 [80]. The two proteins were fused to the fluorescent proteins CyPet and YPet, respectively. To identify the two kinds of inhibitors, the nucleotide exchange on $\mathrm{N} \Delta 17 \mathrm{ARF} 1$ was monitored in real time by measuring the associated enhancement of its intrinsic tryptophan fluorescence, 
while association of the two proteins was simultaneously monitored by measuring the CyPet-to-YPet FRET: the two phenomena increased with similar rates, suggesting GDP/GTP exchange to be rate limiting. As often found, applications of the first assay were limited to the tested compounds that did not act as inner filters for tryptophan excitation, that is, that absorbed negligibly at $280 \mathrm{~nm}$.

Among the fluorescence observables, some have not been employed to investigate the action of small molecules able to interfere with PPIs. A remarkable example is provided by fluorescence cross-correlation spectroscopy (FCCS, [81]). FCCS is a powerful tool to monitor protein-protein and protein-DNA interactions, both in solution and in cells. Measurement of cross correlation between the timefluctuations of the emissions from two different, independently excited probes, each attached to a partner of the interacting pair (or larger assembly), provides information on the complex dynamics and thermodynamics. The FCCS approach suffers from difficulties related with probe binding to the interacting partners, especially for monitoring in cells. The problem, however, has now been solved in many cases by employing different strategies, including autofluorescent labeling, that is, expression of the protein of interest fused with different fluorescent proteins, specific chemical labeling, use of fluorescent antibodies [81], or by employing two-photon excited intrinsic protein fluorescence [82]. The method, now implemented on commercial fluorescence microscopes, is therefore recommended for monitoring perturbation of PPIs by small molecules.

While TR emission from probes has found applications (some are quoted in the previous paragraphs), measurement of the time-course of intrinsic protein emission to monitor changes in the aggregation state is apparently an unexplored opportunity. There are a number of practical reasons that make this kind of experiments poorly apt for medium/HTS: Instrumentation is often expensive, measurements are usually time-consuming, and analysis of the results may be rather complex [83]. While these observations are intimately related with the interactions experienced by tyrosine and tryptophan residues in the protein, and probably reflect even subtle structural changes with an unprecedented sensitivity, a structural/dynamic interpretation of the changes observed in the time-course of a protein emission remains a difficult task (Ref. [29], Chap. 17). However, because of the wealth of information buried within, efforts have been made, and are currently underway, to set up tools and knowledge able to extract this information [33, 83, 84]. Therefore, it is easy to predict TR intrinsic protein fluorescence to become a major source of structural/mechanistic information on PPIs and their modulation.

\subsection{Dissociative Inhibition Kinetics}

While not directly monitoring PPI perturbations by small molecules, whenever a catalytic efficiency depends on some protein multimeric assembly, kinetic analysis can provide direct evidence of the mechanistic consequences of such perturbations. The key observation in these studies is a modulation by small ligands of the 
dependence of specific enzyme activity on protein concentration, that is associated with a mass-balance-law-governed distribution of the protein monomers and various multimers. This effect of added small molecules results from their interfering with the interactions between enzyme subunits usually leading to destabilization of the multimeric assembly.

A few different inhibition models of multimeric enzymes have been proposed that involve destabilization of protein-protein attractive interactions. The inhibitor may bind to some protein sequence that is only exposed during the folding process and thus prevents protein association during folding. In an example of this kind, peptides mimicking one or two $\beta$-strands from the human immunodeficiency virus 1 (HIVl) interface were shown to inhibit the dimeric enzymes, HIVl and HIV2 proteases [85]. A standard kinetic analysis indicated a noncompetitive inhibition mechanism, with, however, no hint at the dimeric nature of the enzyme, or at the possibly dissociative character of the inhibition.

For dimeric enzymes, the analysis of the so-called dissociative inhibition model has been provided in Ref. [86]. An inhibitor of a functionally obligate dimeric enzyme was assumed to bind the dimer (competitive inhibition), the monomer (dissociative inhibition), the dimer-substrate complex (uncompetitive inhibition), or both the dimer and the dimer-substrate complex (noncompetitive inhibition, Fig. 6.4). Resolution of the kinetic scheme in the rapid equilibrium regime led to the expectation that $\mathrm{E}_{0} / \sqrt{ } \mathrm{k}_{\exp }$ versus $\sqrt{ } \mathrm{k}_{\exp }$ plots- $\mathrm{E}_{0}$ being the total enzyme concentration that was varied in the experiments and $\mathrm{k}_{\exp }$ the ratio of the initial reaction rate and the total substrate concentration, which was kept constant-were linear with constant slopes and increasing intercepts at increasing inhibitor concentrations ('Zhang-Poorman plots'). From the best-fit slopes and intercepts, the relevant parameters of the kinetic model were obtained, including the affinities of the inhibitor for the monomeric and the dimeric enzyme, $\mathrm{K}_{\mathrm{I}}$ and $\mathrm{K}_{\mathrm{C}}$, respectively, and the monomer/dimer dissociation constant of the enzyme, $\mathrm{K}_{\mathrm{D}}$. The authors applied their analysis to demonstrate that a tetrapeptide corresponding to the $\mathrm{COOH}$ terminal segment of HIV-1 protease was, indeed, a dissociative inhibitor, that is, it bound to the inactive monomers $(\mathrm{M})$ and prevented their association into the active dimer $\left(\mathrm{M}_{2}\right)$.

In the original model, the inhibition was studied under first-order conditions, that is, the total substrate concentration, [S], was assumed much smaller than $K_{M}$. An alternative solution of the kinetic scheme has been recently obtained without making this assumption, in order to extend the analysis to cases in which fulfillment of this condition would require very small [S] values and the need to measure prohibitively slow reaction kinetics [18].

In the recent literature, conformation of kinetic data to this model, as judged from the linearity of the Zhang-Poorman plots and a significant dependence of the intercepts on inhibitor concentrations, has been shown in a number of examples, many of which concern HIV1 protease dissociative inhibitors. To mention a few, dissociative inhibition was found with some nine-residue peptides obtained through an impressive genetic-selection approach [87], with a 27-residue peptide designed from domains at the $\mathrm{N}$ - and C-termini of the same enzyme [88], with 

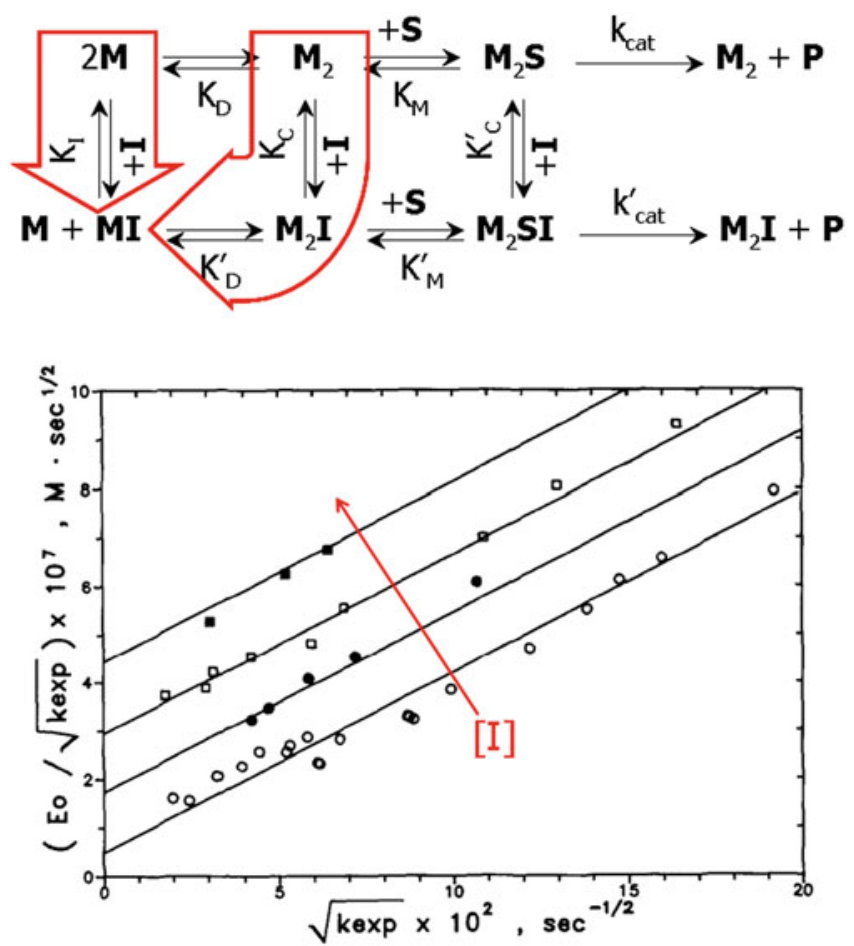

Fig. 6.4 Top kinetic scheme for inhibition of an obligatory dimeric enzyme (adapted from Ref. [86]). Dissociative inhibition is represented by the $M \rightarrow M I$ and/or the $M_{2} \rightarrow M_{2} I \rightarrow M I$ paths (red large arrows). Bottom the dissociative inhibition fingerprint: $E_{0} \sqrt{ } k_{\text {exp }}$ versus $\sqrt{ } k_{\text {exp }}$ plots are parallel lines with intercepts that increase with increasing inhibitor concentration, and the $[I]=0$ line has a non-null intercept (taken from Ref. [86]). The meanings of the symbols are given in the text

some interface peptides cross-linked at their amino termini $[89,90]$ and at side chains [91], with tetracyclic triterpene schisanlactone, a natural product isolated from a fungus [92], and with some naphthalene- and quinoline-based nonpeptidic 'molecular tongs' [93-95]. The above kinetic analysis was corroborated by analytical ultracentrifugation results to characterize some alkyl tripeptides as dissociative inhibitors of the same enzyme, both wild type and mutated [96]. Dissociative inhibition seems to be a useful strategy also versus two other HIV-1 enzymes, reverse transcriptase and IN [97].

Among the fewer examples concerning other dimeric enzymes, we mention the inhibition of dimeric aminoimidazole carboxamide ribonucleotide transformylase (AICAR Tfase) by a small compound, Cappsin 1 [98], and that of 3C-like proteinase of severe acute respiratory syndrome coronavirus by some octapeptides derived from the protein N-terminal [99]. Apparently, no available examples involve more-than-dimeric enzymes, and the dissociative inhibition model has not been extended to higher oligomers than dimers. 
Of some interest is the mechanistic issue concerning whether a supposed inhibitor of a dimeric enzyme preferentially binds the enzyme monomer, thus preventing its association with another monomer to obtain the active dimer, or binds the already formed dimer causing its disruption. The two paths may require quite different molecular properties for an efficient inhibitor, and, as a consequence, different molecular design strategies. The kinetic model in Fig. 6.4 encompasses both mechanistic routes, that we may simplify as, respectively, $\mathrm{M} \rightarrow \mathrm{MI}$ and $\mathrm{M}_{2} \rightarrow \mathrm{M}_{2} \mathrm{I} \rightarrow \mathrm{MI}$, and characterizes them through the corresponding equilibrium constants, $\mathrm{K}_{\mathrm{I}}$ and $\mathrm{K}_{\mathrm{C}} \mathrm{K}_{\mathrm{D}}$ '. Should one path be much slower than the other and the corresponding equilibration not attained in the experimental runs, a more sophisticated kinetic analysis involving all the relevant rate constants and more detailed TR experimental information would likely be necessary to conclude which of the two kinetic paths proposed remains the only functionally relevant one.

Lastly, we remark that dissociative inhibition is not the only mechanism by which a small molecule can inhibit a multimeric obligate enzyme. Kinetic analysis, in combination with crystallographic and calorimetric evidence, showed that inhibition of Trypanosoma cruzi triosephosphate isomerase was caused by a small molecule whose binding triggered evolution of the dimeric protein toward an inactive conformation, rather than to dimer disruption. The nonlinear dependence of pseudo-first-order constants of inactivation on inhibitor concentration provided information on the complex inhibition mechanism [100]. As briefly reported in paragraph 2.3, use of FRET between probes enabled the authors to rule out a dissociative mechanism to interpret inhibition of dimeric human TS by some octapeptides designed from a sequence in the inter-monomer surface [63]. Experimental evidence, kinetic, crystallographic, and calorimetric, led to the conclusion that the peptides selectively bound to a dimeric, inactive conformation of the protein, thus stabilizing it. A specific kinetic scheme was solved under the usual fast equilibrium assumption and was shown to be consistent with the observed noncompetitive kinetic behavior with, however, modified interpretations of the plot slopes, intercepts, and crossing point.

Acknowledgements This work supported by the Italian Association for Cancer Research (AIRC), grant AIRC-DROC IG 10474.

\section{References}

1. Weiss A, Schlessinger J (1998) Switching signals on or off by receptor dimerization. Cell 94:277-280

2. Fry DC, Vassilev LT (2005) Targeting protein-protein interactions for cancer therapy. J Mol Med 83:955-963

3. Stites WE (1997) Protein-protein interactions: interface structure, binding thermodynamics, and mutational analysis. Chem Rev 97:1233-1250

4. Block P, Weskamp N, Wolf A, Klebe G (2007) Strategies to search and design stabilizers of protein-protein interactions: a feasibility study. Proteins: Struct, Funct, Bioinf 681:70-186 
5. Silvian LF, Friedman JE, Strauch K, Cachero TG, Day ES, Qian F, Cunningham B, Fung A, Sun L, Su L, Zheng Z, Kumaravel G, Whitty A (2011) Small molecule inhibition of the TNF family cytokine CD40 ligand through a subunit fracture mechanism. ACS Chem Biol 6:636-647

6. Wilson CGM, Arkin MR (2011) Small-molecule inhibitors of IL-2/IL-2R: lessons learned and applied. In: Vassiliev L, Fry D (eds) Small-molecule inhibitors of protein-protein interactions. Curr Top Microbiol, vol. 348. Springer, Berlin

7. Thangudu RR, Bryant SH, Panchenko AR, Madej T (2012) Modulating protein-protein interactions with small molecules: the importance of binding hotspots. J Mol Biol 415:443-453

8. Berg T (2003) Modulation of protein-protein interactions with small organic molecules. Angew Chem Int Ed 42:2462-2481

9. Braisted AC, Oslob JD, Delano WL, Hyde J, McDowell RS, Waal N, Yu C, Arki MR, Raimundo BC (2003) Discovery of a potent small molecule IL-2 inhibitor through fragment assembly. J Am Chem Soc 125:3714-3715

10. Arkin MR, Wells JA (2004) Small-molecule inhibitors of protein-protein interactions: progressing towards the dream. Nat Rev Drug Discov 3:301-317

11. Phizicky EM, Fields S (1995) Protein-protein interactions: methods for detection and analysis. Microbiol Rev 59(1):94-123

12. Lakey JH, Raggett EM (1998) Measuring protein-protein interactions. Curr Opin Struc Biol 8:119-123

13. Piehler $\mathbf{J}$ (2005) New methodologies for measuring protein interactions in vivo and in vitro. Curr Opin Struc Biol 15:4-14

14. Shoemaker BA, Panchenko AR (2007) Deciphering protein-protein interactions. Part I. Experimental techniques and databases. PLoS Comput Biol 3:337-344

15. Heeres JT, Hergenrother PJ (2011) High-throughput screening for modulators of proteinprotein interactions: use of photonic crystal biosensors and complementary technologies. Chem Soc Rev 40:4398-4410

16. Vaynberg J, Qin J (2006) Weak protein-protein interactions as probed by NMR spectroscopy. Trends Biotechnol 24:22-27

17. Arakawa T, Philo JS, Ejima D, Tsumoto K, Arisaka F (2007) Aggregation analysis of therapeutic proteins. Part 2. Analytical ultracentrifugation and dynamic light scattering. Bioprocess Int 5:36-47. http://www.ap-lab.com/Part2.pdf

18. Cardinale D, Salo-Ahen OMH, Ferrari S, Ponterini G, Cruciani G, Carosati E, Tochowicz AM, Mangani S, Wade RC, Costi MP (2010) Homodimeric enzymes as drug targets. Curr Med Chem 17:826-846

19. Arakawa T, Philo JS, Ejima D, Tsumoto K, Arisaka F (2006) Aggregation analysis of therapeutic proteins. Part 1. General aspects and techniques for assessment. Bioprocess Int 4:42-43. http://www.ap-lab.com/Bioprocess_Intl_Aggregation_Part1.pdf

20. Patapoff TW, Mrsny RJ, Lee WA (1993) The application of size exclusion chromatography and computer simulation to study the thermodynamic and kinetic parameters for short-lived dissociable protein aggregates. Anal Biochem 212:71-78

21. Hall D, Huang L (2012) On the use of size exclusion chromatography for the resolution of mixed amyloid aggregate distributions: I. equilibrium partition models. Anal Biochem 426:69-85

22. Karlsson R (2004) SPR for molecular interaction analysis: a review of emerging application areas. J Mol Recognit 17:151-161

23. Raimundo BC, Oslob JD, Braisted AC, Hyde J, McDowell RS, Randal M, Waal ND, Wilkinson J, Yu CH, Arkin MR (2004) Integrating fragment assembly and biophysical methods in the chemical advancement of small-molecule antagonists of IL-2: an approach for inhibiting protein-protein interactions. J Med Chem 47:3111-3130

24. Vassilev LT, Vu BT, Graves B, Carvajal D, Podlaski F, Filipovic Z, Kong N, Kammlott U, Lukacs C, Klein C, Fotouhi N, Liu EA (2004) In vivo activation of the p53 pathway by small-molecule antagonists of MDM2. Science 303:844-848 
25. Van der Merwe PA (2000) Surface plasmon resonance. In: Harding S, Chowdhry PZ (eds) Protein-ligand interactions: a practical approach. Oxford University Press, New York

26. Zuiderweg ERP (2002) Mapping protein-protein interactions in solution by NMR spectroscopy. Biochemistry 41:1-7

27. Morris MA (2010) Fluorescent biosensors of intracellular targets from genetically encoded reporters to modular polypeptide probes. Cell Biochem Biophys 56:19-37

28. Valeur B (2002) Molecular fluorescence. Principles and applications. Wiley-VCH, Weinheim

29. Lakowicz JR (2006) Principles of fluorescence spectroscopy. Springer, New York

30. Otto-Bruc A, Antonny B, Vuong TM, Chardin P, Chabré M (1993) Interaction between the retinal cyclic GMP phosphodiesterase inhibitor and transducin. Kinetics and affinity studies. Biochemistry 32:8636-8645

31. Marion JD, Van DN, Bell JE, Bell JK (2010) Measuring the effect of ligand binding on the interface stability of multimeric proteins using dynamic light scattering. Anal Biochem 407:278-280

32. Zutshi R, Franciskovich J, Shultz M, Schweitzer B, Bishop P, Wilson M, Chmielewski J (1997) Targeting the dimerization interface of HIV-1 protease: inhibition with cross-linked interfacial peptides. J Am Chem Soc 119:4841-4845

33. Engelborghs Y (2001) The analysis of time resolved protein fluorescence in multitryptophan proteins. Spectrochim Acta A 57:2255-2270

34. Maithal K, Ravindra G, Nagaraj G, Kumar Singh S, Balaram H, Balaram P (2002) Subunit interface mutation disrupting an aromatic cluster in Plasmodium falciparum triosephosphate isomerase: effect on dimer stability. Prot Eng 15:575-584

35. Garai K, Frieden C (2010) The association-dissociation behavior of the ApoE proteins: kinetic and equilibrium studies. Biochemistry 49:9533-9541

36. Kipp RA, Case MA, Wist AD, Cresson CM, Carrell M, Griner E, Wiita A, Albiniak PA, Chai J, Shi Y, Semmelhack MF, McLendon GL (2002) Molecular targeting of inhibitor of apoptosis proteins based on small molecule mimics of natural binding partners. Biochemistry 41:7344-7349

37. Kersten S, Pan L, Chambon P, Gronemeyer H, Nay N (1995) Role of ligand in retinoid signaling. 9-cis-Retinoic acid modulates the oligomeric state of the retinoid $\mathrm{X}$ receptor. Biochemistry 34:13717-13721

38. Khanna M, Chelladurai B, Gavini A, Li L, Shao M, Courtney D, Turchi JJ, Matei D, Meroueh S (2011) Targeting ovarian tumor cell adhesion mediated by tissue transglutaminase. Mol Cancer Ther 10:626-636

39. Liu Z, Sun C, Olejniczak ET, Meadows RP, Betz SF, Oost T, Herrmann J, Wu JC, Fesik SW (2000) Structural basis for binding of Smac/DIABLO to the XIAP BIR3 domain. Nature 408:1004-1008

40. Sun H, Nikolovska-Coleska Z, Yang C-Y, Xu L, Liu M, Tomita Y, Pan H, Yoshioka Y, Krajewski K, Roller PP, Wang S (2004) Structure-based design of potent conformationally constrained Smac mimetics. J Am Chem Soc 126:16686-16687

41. Oost TK, Sun C, Armstrong RC, Al-Assaad A-S, Betz SF, Deckwerth TL, Ding H, Elmore SW, Meadows RP, Olejniczak ET, Oleksijew A, Oltersdorf T, Rosenberg SH, Shoemaker AR, Tomaselli KJ, Zou H, Fesik SW (2004) Discovery of potent antagonists of the antiapoptotic protein XIAP for the treatment of cancer. J Med Chem 47:4417-4426

42. Buckley DL, Van Molle I, Gareiss PC, Tae HS, Michel J, Noblin DJ, Jorgensen WL, Ciulli A, Crews CM (2012) Targeting the von Hippel-Lindau E3 ubiquitin ligase using small molecules to disrupt the VHL/HIF-1 $\alpha$ interaction. J Am Chem Soc 134:4465-4468

43. Leone M, Zhai D, Saret S, Kitada S, Reed JC, Pellecchia M (2003) Cancer prevention by tea polyphenols is linked to their direct inhibition of antiapoptotic Bcl-2-family proteins. Cancer Res 63:8118-8121

44. Wang J-L, Liu D, Zhang Z-J, Shan S, Han X, Srinivasula SM, Croce CM, Alnemri ES, Huang Z (2000) Structure-based discovery of an organic compound that binds Bcl-2 protein and induces apoptosis of tumor cells. P Natl Acad Sci USA 97:7124-7129 
45. Enyedy IJ, Ling Y, Nacro K, Tomita Y, Wu X, Cao Y, Guo R, Li B, Zhu X, Huang Y, Long Y-Q, Roller PP, Yang D, Wang S (2001) Discovery of small-molecule inhibitors of Bcl-2 through structure-based computer screening. J Med Chem 44:4313-4324

46. Degterev A, Lugovskoy A, Cardone M, Mulley B, Wagner G, Mitchison T, Yuan J (2001) Identification of small-molecule inhibitors of interaction between the $\mathrm{BH} 3$ domain and BclXL. Nat Cell Biol 3:173-182

47. Chan S-L, Lee MC, Tan KO, Yang L-K, Lee ASY, Flotow H, Fu NY, Butler MS, Soejarto $\mathrm{DD}$, Buss AD, Yu VC (2003) Identification of chelerythrine as an inhibitor of Bcl-XL function. J Biol Chem 278:20453-20456

48. Yin H, Hamilton AD (2004) Terephthalamide derivatives as mimetics of the helical region of BAK peptide target Bcl-XL protein. Bioorg Med Chem Lett 14:1375-1379

49. Rush TS, Grant JA, Mosyak L, Nicholls A (2005) A shape-based 3-D scaffold hopping method and its application to a bacterial protein-protein interaction. J Med Chem 48:1489-1495

50. Zhao J, Du Y, Horton JR, Upadhyay AK, Lou B, Bai Y, Zhang X, Du L, Li M, Wang B, Zhang L, Barbieri JT, Khuri FR, Cheng X, Fu H (2011) Discovery and structural characterization of a small molecule 14-3-3 protein-protein interaction inhibitor. P Natl Acad Sci USA 108:16212-16216

51. Caselli M, Latterini L, Ponterini G (2004) Consequences of H-dimerization on the photophysics and photochemistry of oxacarbocyanines. Phys Chem Chem Phys 6:3857-3863

52. He MM, Stroustrup Smith A, Oslob JD, Flanagan WM, Braisted AC, Whitty A, Cancilla MT, Wang J, Lugovskoy AA, Yoburn JC, Fung AD, Farrington G, Eldredge JK, Day ES, Cruz LA, Cachero TG, Miller SK, Friedman JE, Choong IC, Cunningham BC (2005) Smallmolecule inhibition of TNF- $\alpha$. Science 310:1022-1025

53. Prasanna V, Bhattacharjya S, Balaram P (1998) Synthetic interface peptides as inactivators of multimeric enzymes: inhibitory and conformational properties of three fragments from Lactobacillus casei thymidylate synthase. Biochemistry 37:6883-6893

54. Grasberger BL, Lu T, Schubert C, Parks DJ, Carver TE, Koblish HK, Cummings MD, LaFrance LV, Milkiewicz KL, Calvo RR, Maguire D, Lattanze J, Franks CF, Zhao S, Ramachandren K, Bylebyl GR, Zhang M, Manthey CL, Petrella EC, Pantoliano MW, Deckman IC, Spurlino JC, Maroney AC, Tomczuk BE, Molloy CJ, Bone RF (2005) Discovery and cocrystal structure of benzodiazepinedione HDM2 antagonists that activate p53 in cells. J Med Chem 48:909-912

55. Tzung S-P, Kim KM, Basañez G, Giedt CD, Simon J, Zimmerberg J, Zhang KYJ, Hockenbery DM (2001) Antimycin A mimics a cell-death-inducing Bcl-2 homology domain 3. Nat Cell Biol 3:183-191

56. Kim KM, Giedt CD, Basañez G, O’Neill JW, Hill JJ, Han Y-H, Tzung S-P, Zimmerberg J, Hockenbery DM, Zhang KYJ (2001) Biophysical characterization of recombinant human Bcl-2 and its interactions with an inhibitory ligand, antimycin A. Biochemistry 40:4911-4922

57. Koivunen Nissinen L, Käpylä J, Jokinen J, Pihlavisto M, Marjamäki A, Heino J, Huuskonen J, Pentikäinen OT (2011) Fluorescent small molecule probe to modulate and explore $\alpha 2 \beta 1$ integrin function. J Am Chem Soc 133:14558-14561

58. Cosa G, Focsaneanu K-S, McLean JRN, McNamee JP, Scaiano JC (2001) Photophysical properties of fluorescent DNA-dyes bound to single- and double-stranded DNA in aqueous buffered solution. Photochem Photobiol 73:585-599

59. Visser AJWG, Laptenok SP, Visser NV, van Hoek A, Birch DJS, Brochon J-C, Borst JW (2010) Time-resolved FRET fluorescence spectroscopy of visible fluorescent protein pairs. Eur Biophys J 39(2):241-253

60. Truong K, Ikura M (2001) The use of FRET imaging microscopy to detect protein-protein interactions and protein conformational changes in vivo. Curr Opin Struc Biol 11:573-578

61. Li HY, Ng EKO, Lee SMY, Kotaka M, Tsui SKW, Lee CY, Fung KP, Waye MMY (2001) Protein-protein interaction of FHL3 with FHL2 and visualization of their interaction by 
green fluorescent proteins (GFP) two-fusion fluorescence resonance energy transfer (FRET). J Cell Biochem 80:293-303

62. Genovese F, Ferrari S, Guaitoli G, Caselli M, Costi MP, Ponterini G (2010) Dimermonomer equilibrium of human thymidylate synthase monitored by fluorescence resonance energy transfer. Protein Sci 19:1023-1030

63. Cardinale D, Guaitoli G, Tondi D, Luciani R, Henrich S, Salo-Ahen OMH, Ferrari S, Marverti G, Guerrieri D, Ligabue A, Frassineti C, Pozzi C, Mangani S, Fessas D, Guerrini R, Ponterini G, Wade RC, Costi MP (2011) Protein-protein interface-binding peptides with a novel inhibitory mechanism against the cancer target, human thymidylate synthase. P Natl Acad Sci USA 108:E542-E549

64. Li C, Reddy TRK, Fischer PM, Dekker LV (2010) A Cy5-labeled S100A10 tracer used to identify inhibitors of the protein interaction with annexin A2. Assay Drug Dev Techn 8:85-95

65. Tsiang M, Jones GS, Hung M, Mukund S, Han B, Liu X, Babaoglu K, Lansdon E, Chen X, Todd J, Cai T, Pagratis N, Sakowicz R, Geleziunas R (2009) Affinities between the binding partners of the HIV-1 integrase dimer/lens epithelium derived growth factor (IN dimer/ LEDGF) complex. J Biol Chem 284:33580-33599

66. Tsiang M, Jones GS, Hung M, Samuel D, Novikov N, Mukund S, Brendza KM, NiedzielaMajka A, Jin D, Liu X, Mitchell M, Sakowicz R, Geleziunas R (2011) Dithiothreitol causes HIV-1 integrase dimer dissociation while agents interacting with the integrase dimer interface promote dimer formation. Biochemistry 50:1567-1581

67. Levitt JA, Matthews DR, Ameer-Beg SM, Suhling K (2009) Fluorescence lifetime and polarization-resolved imaging in cell biology. Curr Opin Biotech 20:28-36

68. Ganguly S, Clayton AHA, Chattopadhyay A (2011) Organization of higher-order oligomers of the serotonin $_{1 \mathrm{~A}}$ receptor explored utilizing homo-FRET in live cells. Biophys $\mathrm{J}$ 100:361-368

69. Bader AN, Hofman EG, Voortman J, Gerritsen HC, van Bergen En Henegouwen PMP (2009) Homo-FRET imaging enables quantification of protein cluster sizes with subcellular resolution. Biophys J 97(9):2613-2622

70. Hofman EG, Bader AN, Voortman J, van den Heuvel DJ, Sigismund S, Verkleij AJ, Gerritsen HC, van Bergen en Henegouwen PMP (2010) Ligand-induced EGF receptor oligomerization is kinase-dependent and enhances internalization. J Biol Chem 285:39481-39489

71. Hemmila I, Laitala V (2005) Progress in lanthanides as luminescent probes. J Fluoresc 15:529-542

72. Tu D, Liu L, Ju Q, Liu Y, Zhu H, Li R, Chen X (2011) Time-resolved FRET biosensor based on amine-functionalized lanthanide-doped $\mathrm{NaYF}_{4}$ nanocrystals. Angew Chem Int Ed 50:6306-6310

73. Kota S, Scampavia L, Spicer T, Beeler AB, Takahashi V, Snyder JK, Porco JA Jr, Hodder P, Strosberg AD (2010) A time-resolved fluorescence-resonance energy transfer assay for identifying inhibitors of hepatitis C virus core dimerization. Assay Drug Dev Techn 8:96-105

74. Liu G, Link JT, Pei Z, Reilly EB, Leitza S, Nguyen B, Marsh KC, Okasiski GF, von Geldern TW, Ormes M, Fowler K, Gallatin M (2000) Discovery of novel p-arylthio cinnamides as antagonists of leukocyte function-associated antigen-1/intracellular adhesion molecule-1 interaction. 1. Identification of an addition binding pocket based on an anilino diaryl sulfide lead. J Med Chem 43:4025-4040

75. Pei Z, Xin Z, Liu G, Li Y, Reilly EB, Lubbers NL, Huth JR, Link JT, von Geldern TW, Cox BF, Leitza S, Gao Y, Marsh KC, DeVries P, Okasinski GF (2001) Discovery of potent antagonists of leukocyte function-associated antigen-1/intercellular adhesion molecule-1 interaction. 3.Amide (C-ring) structure-activity relationship and improvement of overall properties of arylthio cinnamides. J Med Chem 44:2913-2920

76. Gotoh Y, Nagata H, Kase H, Shimonishi M, Ido M (2010) A homogeneous time-resolved fluorescence-based high-throughput screening system for discovery of inhibitors of IKK $\beta$ NEMO interaction. Anal Biochem 405:19-27 
77. Blazer LL, Roman DL, Chung A, Larsen MJ, Greedy BM, Husbands SM, Neubig RR (2010) Reversible, allosteric small-molecule inhibitors of regulator of G protein signaling proteins. Mol Pharmacol 78:524-533

78. Coward P, Conn M, Tang J, Xiong F, Menjares A, Reagan JD (2009) Application of an allosteric model to describe the interactions among retinol binding protein 4, transthyretin, and small molecule retinol binding protein 4 ligands. Anal Biochem 384:312-320

79. Markowitz J, Chen I, Gitti R, Baldisseri DM, Pan Y, Udan R, Carrier F, MacKerell AD, Weber DJ (2004) Identification and characterization of small molecule inhibitors of the calcium-dependent S100B-p53 tumor suppressor interaction. J Med Chem 47:5085-5093

80. Bill A, Blockus H, Stumpfe D, Bajorath J, Schmitz A, Famulok M (2011) A homogeneous fluorescence resonance energy transfer system for monitoring the activation of a protein switch in real time. J Am Chem Soc 133:8372-8379

81. Langowski J (2008) Protein-protein interactions determined by fluorescence correlation spectroscopy. Method Cell Biol 85:471-484

82. Sahoo B, Balaji J, Nag S, Kaushalya SK, Maiti S (2008) Protein aggregation probed by twophoton fluorescence correlation spectroscopy of native tryptophan. J Chem Phys 129:075103-1-075103-5

83. Lee JC, Langen R, Hummel PA, Gray HB, Winkler JR (2004) $\alpha$-Synuclein structures from fluorescence energy-transfer kinetics: implications for the role of the protein in Parkinson's disease. P Natl Acad Sci USA 101:16466-16471

84. Engelborghs Y (2003) Correlating protein structure and protein fluorescence. J Fluoresc 13:9-16

85. Babé LM, Rose J, Craik CS (1992) Synthetic "interface" peptides alter dimeric assembly of the HIV 1 and 2 proteases. Protein Sci 1:1244-1253

86. Zhang Z-Y, Poorman RA, Maggiora LL, Heinrikson RL, Kezdy FJ (1991) Dissociative inhibition of dimeric enzymes. J Biol Chem 266:15591-15594

87. Park S-H, Raines RT (2000) Genetic selection for dissociative inhibitors of designated protein-protein interactions. Nat Biotech 18:847-851

88. Davis DA, Brown CA, Singer KE, Wang V, Kaufman J, Stahl SJ, Wingfield P, Maedaa K, Harada S, Yoshimura K, Kosalaraksa P, Mitsuya H, Yarchoan R (2006) Inhibition of HIV-1 replication by a peptide dimerization inhibitor of HIV-1 protease. Antivir Res 72:89-99

89. Hwang YS, Chmielewski J (2005) Development of low molecular weight HIV-1 protease dimerization inhibitors. J Med Chem 48:2239-2242

90. Lee S-G, Chmielewski J (2006) Rapid synthesis and in situ screening of potent HIV-1 protease dimerization inhibitors. Chem Biol 13:421-426

91. Bowman MJ, Chmielewski J (2009) Sidechain-linked inhibitors of HIV-1 protease dimerization. Bioorg Med Chem 17:967-976

92. El Dine RS, El Halawany AM, Ma C-M, Hattori M (2009) Inhibition of the dimerization and active site of HIV-1 protease by secondary metabolites from the vietnamese mushroom Ganoderma colossum. J Nat Prod 72:2019-2023

93. Merabet N, Dumond J, Collinet B, Van Baelinghem L, Boggetto N, Ongeri S, Ressad F, Reboud-Ravaux M, Sicsic S (2004) New constrained "molecular tongs" designed to dissociate HIV-1 protease dimer. J Med Chem 47:6392-6400

94. Bannwarth L, Kessler A, Pèthe S, Collinet B, Merabet N, Boggetto N, Sicsic S, ReboudRavaux M, Ongeri S (2006) Molecular tongs containing amino acid mimetic fragments: new inhibitors of wild-type and mutated HIV-1 protease dimerization. J Med Chem 49:4657-4664

95. Vidu A, Dufau L, Bannwarth L, Soulier J-L, Sicsic S, Piarulli U, Reboud-Ravaux M, Ongeri S (2010) Toward the first nonpeptidic molecular tong inhibitor of wild-type and mutated HIV-1 protease dimerization. Chem Med Chem 5:1899-1906

96. Bannwarth L, Rose T, Dufau L, Vanderesse R, Dumond J, Jamart-Grégoire B, Pannecouque C, De Clercq E, Reboud-Ravaux M (2009) Dimer disruption and monomer sequestration by alkyl tripeptides are successful strategies for inhibiting wild-type and multidrug-resistant mutated HIV-1 proteases. Biochemistry 48:379-387 
97. Camarasa M-J, Velàzquez S, San-Fèlix A, Pérez-Pérez MJ, Gago F (2006) Dimerization inhibitors of HIV-1 reverse transcriptase, protease and integrase: a single mode of inhibition for the three HIV enzymes? Antivir Res 71:260-267

98. Capps KJ, Humiston J, Dominique R, Hwang I, Boger DL (2005) Discovery of AICAR Tfase inhibitors that disrupt requisite enzyme dimerization. Bioorg Med Chem Lett 15:2840-2844

99. Wei P, Fan K, Chen H, Ma L, Huang C, Tan L, Xi D, Li C, Liu Y, Cao A, Lai L (2006) The N-terminal octapeptide acts as a dimerization inhibitor of SARS coronavirus 3C-like proteinase. Biochem Bioph Res Co 339:865-872

100. Téllez-Valencia A, Olivares-Illana V, Hernàndez-Santoyo A, Pèrez-Montfort R, Costas M, Rodrìguez-Romero $\mathrm{A}$, Lòpez-Calahorra $\mathrm{F}$, Tuena de Gòmez-Puyou $\mathrm{M}$, Gòmez-Puyou A (2004) Inactivation of triosephosphate isomerase from Trypanosoma cruzi by an agent that perturbs its dimer interface. J Mol Biol 341:1355-1365 